\title{
The Nutritional Status of Patients with Diffuse Large B cell Lymphoma Does it Matter?
}

\begin{abstract}
Background: Nutritional status of lymphoma is not routinely assessed. The aim of this study was to assess nutritional status at the beginning of the treatment and to evaluate its value as predictor of progression free survival.

Methodology: This study embraced 77 male and 73 female patients with confirmed Non Hodgkin diffuse large B cell lymphoma treatment naive, treated with R-CHOP in period November 2011 and June 2016. Previous revised international prognostic score (R-IPI) was taken into consideration. Nutritional status was assessed by using Nutritional risk score (NRS2002). New score was made by adding nutritional assessment.

Results: In our group $81(54 \%)$ patients were over $>60$ years, 92(61.3\%) had clinical stage $\geq 111,61$ (40.7\%) had elevated LDH, 79 (52.7\%) had Eastern Cooperative Oncology Group performance status (ECOG PS) $\geq 2$, extranodal disease was present in $60(40 \%)$. According to NRS2002 $89(59.3 \%$ ) had score $\geq 3$, BMl $\leq 20.5 \mathrm{~kg} / \mathrm{m} 223(14.7 \%)$ and $50(33.3 \%)$ had weight loss over $10 \%$ for past 6 months. Nutritional status was significantly different in patients with worse ECOG PS. Patients with NRS2002 score $\geq 5$, identifying patients with severe malnutrition, had shorter PFS (Mean: 19.4 with 95\%, Cl: 8.23-29.88 months) than groups with normal (Mean: 56.7 with $95 \% \mathrm{Cl}$ : 52.2-61 months) or in risk of malnutrition ( 42.3 with $95 \% \mathrm{Cl} 34.4-50.3$ months), $\mathrm{p} \leq 0.001$. New IPI-NRS $\geq 4$ can identify patients with short PFS.

Conclusion: NRS 2002 assessment seems to be useful tool as a predictor of PFS in patients with diffuse large B cell lymphoma. Adding it to widely used IPI can we better predict the outcome.
\end{abstract}

\section{Introduction}

The lymphomas are heterogeneous group of neoplasms in which the malignant cells derive from lymphocytes, originating in the bone marrow [1]. Diffuse Large B Cell Lymphoma (DLBCL) is the most common subtype of aggressive lymphoma accounting about $50 \%$ of NHL cases [1]. Combination chemotherapy has transformed aggressive NHL prognosis from fatal disease into one that is often curable [2]. However, there are still patients that are dying from the disease and we need accurate prognostic scores to identify groups with differing prognoses that can help in guiding management decisions and provide useful information for the patient $[1,2]$. The International Prognostic Index (IPI) is widely used to predict the outcome of patients according to age, clinical stage, the Elevation of Lactate Dehydrogenase (LDH), Eastern Cooperative Oncology Group Performance Status (ECOG PS) and extranodal involvement [2]. Now days, we certainly know that DLBCL is very heterogeneous disease and we need additional parameters to enchase accuracy of predictive score. The pretreatment nutritional status in DLBCL is not routinely assessed. Recently, there are some reports evaluating the effect of nutritional status on the survival outcome in patients with DLBCL [3]. Also, there are several different scores available for the nutritional screening. The European Society for Clinical Nutrition

\section{Journal of}

Nutrition and Health

Djurasinovic $V^{1,2^{*}}$, Sipetic-Grujicic $S^{2,3}$, Antic $D^{1,2}$, Vukovic $\mathrm{V}^{2}$, Bila $\mathrm{J}^{1,2}$, Sretenovic $\mathrm{A}^{2}$, OtasevicV ${ }^{2}$ and Mihaljevic $\mathbf{B}^{1,2}$

${ }^{\prime}$ Clinic for Hematology, Clinical Center of Serbia, Serbia

${ }^{2}$ Faculty of Medicine, University of Belgrade, Serbia

${ }^{3}$ Institute for Epidemiology, University of Belgrade, Serbia

\section{*Address for Correspondence}

Vladislava Djurasinovic, Faculty of medicine, Clinic for Hematology, Clinical Center of Serbia , University of Belgrade, Koste Todorovica 2, 11000 Belgrade, Serbia, Phone: +381642618321; E-mail: vladislavadj@yahoo.co.uk

Submission: 27, August 2018

Accepted: 17, September 2018

Published: 24, September 2018

Copyright: @ 2018 Djurasinovic V, et al. This is an open access article distributed under the Creative Commons Attribution License, which permits unrestricted use, distribution, and reproduction in any medium, provided the original work is properly cited.

and metabolism (ESPEN) proposed "Nutritional Risk Screening 2002" (NRS2002) [4]. This score includes the percentage of weight loss, Body Mass Index (BMI), the aggressiveness of the disease and age. The "Mini Nutritional Assessment" (MNA) is commonly used in the older population of patients and includes loss of appetite, activity, depression and scale of BMI [5].

The aim of our study was to evaluate the pretreatment nutritional status in patients with aggressive and most frequent type of non Hodgkin lymphoma-DLBCL. Secondary aim was to assess survival analysis taking into account nutritional status among other clinical parameters.

\section{Methodology}

Our study embraced 150 pts, 77 male and 73 female, with newly diagnosed NHL DLBCL who required treatment at the Clinic for Hematology, Clinical Centre of Serbia, in the period between

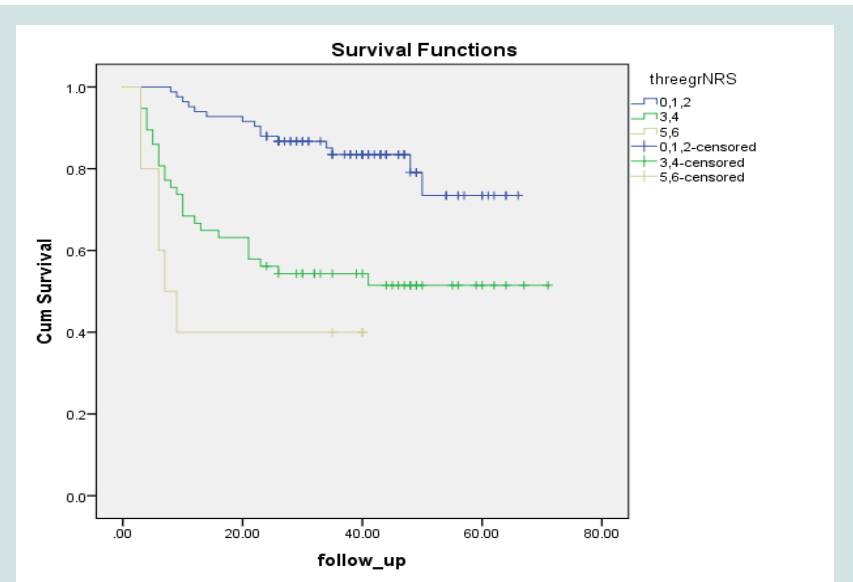

Graph 1: Kaplan Meir curve in progression free survival according NRS2002 assessment. 
Citation: Djurasinovic V, Sipetic-Grujicic S, Antic D, Vukovic V, Bila J, et al. The Nutritional Status of Patients with Diffuse Large B cell Lymphoma Does it Matter?. J Nutri Health. 2018;4(2): 4.

ISSN: $2469-4185$

Table 1: Demographic and clinical characteristics of patients.

\begin{tabular}{|c|c|c|}
\hline Gender & Number & $\%$ \\
\hline Male & 77 & 51.3 \\
\hline Female & 73 & 48.7 \\
\hline \multicolumn{3}{|l|}{ Age } \\
\hline$\leq 60$ years & 69 & $46 \%$ \\
\hline$>60$ years & 81 & $54 \%$ \\
\hline \multicolumn{3}{|l|}{ Clinical stage } \\
\hline $\mathrm{I}, \mathrm{II}$ & 58 & $38.7 \%$ \\
\hline III, IV & 92 & $61.3 \%$ \\
\hline \multicolumn{3}{|l|}{ elevated LDH } \\
\hline Yes & 61 & $40.7 \%$ \\
\hline No & 89 & $59.3 \%$ \\
\hline \multicolumn{3}{|l|}{ ECOG PS } \\
\hline 0,1 & 71 & $41.3 \%$ \\
\hline$\geq 2$ & 79 & $52.7 \%$ \\
\hline \multicolumn{3}{|l|}{ Extranodal diseas } \\
\hline Yes & 60 & $40 \%$ \\
\hline No & 90 & $60 \%$ \\
\hline \multicolumn{3}{|l|}{ NRS } \\
\hline$\leq 2$ & 61 & $40.7 \%$ \\
\hline$\geq 3$ & 89 & $59.3 \%$ \\
\hline \multicolumn{3}{|l|}{ Treatment outcome } \\
\hline CR & 51 & $34.0 \%$ \\
\hline PR & 56 & $35.7 \%$ \\
\hline Early death (within 12 m) & 13 & $8.7 \%$ \\
\hline Early relapse & 25 & $16.7 \%$ \\
\hline Stable/progressive disease & 5 & $3.3 \%$ \\
\hline BMI & $26,47(95 \% \mathrm{Cl})$ & $22.85-30.08$ \\
\hline$\leq 20,5 \mathrm{~kg} / \mathrm{me} 2$ & 23 & $14.7 \%$ \\
\hline$>20,5 \mathrm{~kg} / \mathrm{me} 2$ & 127 & $81.4 \%$ \\
\hline \multicolumn{3}{|l|}{ Weight loss } \\
\hline $0-10 \%$ & 100 & $66.7 \%$ \\
\hline$\geq 10 \%$ & 50 & $33.3 \%$ \\
\hline \multicolumn{3}{|l|}{ Pathohistology } \\
\hline DLBCL NOS & 143 & $95.3 \%$ \\
\hline Mediastinal & 5 & $3.3 \%$ \\
\hline Leg type & 2 & $1.3 \%$ \\
\hline
\end{tabular}

November 2011 and June 2016. All included patients were between 18 and 85 years old with newly diagnosed NHL DLBCL, previously untreated. They were all informed about the nutritional assessment and agreed to participate in the study. Study was approved from Ethical Committee of Clinical center of Serbia. All patients received curative treatment with rituximab and $\mathrm{CHOP}$ or $\mathrm{CHOP}$-like combination. Patients with more co-morbidities and non-compliant for curable treatment were excluded from the study. From the medical records we have collected data about age, clinical stage, ECOG PS, weight at the beginning of the treatment, weight loss, and type of treatment and result of therapy outcome. Risk was calculated according to age and Clinical Stage (CS) graded in accordance with the Ann Arbor classification [6]. According to ECOG PS, all the pts were divided into two groups: ECOG PS $<2$, and $\geq 2$, which is also a part of the IPI score. Nutritional status was screened using NRS2002. All pts with grade $\geq 3$ were considered as malnourished or in risk for malnutrition. Also we had the information about extranodal involvement. Therapy outcome was assessed using criteria for lymphoma assessment as Complete Remission (CR), Partial Remission (PR), Early Death (ED), Early Relapse (ER), Stable Disease (SD) or Progressive Disease (PD).
The outcomes CR, VGPR and PR were considered favorable and PD, $\mathrm{SD}, \mathrm{ED}$ or ER as unfavorable. Median follow up for progression free survival was 35 (3-71) months and survival analysis was performed.

\section{Statistical analysis}

The statistical package SPSS 20 was used for the statistical evaluation of the results. The descriptive statistics, $\chi^{2}$ test and Fisher test for evaluating the differences between frequencies in groups were used. Survival outcome was evaluated using Kaplan-Meier curves, while the Log-Rank and Breslow test were used for calculating the differences in the groups.

\section{Results}

There were 150 pts with non-Hodgkin DLBCL lymphoma eligible for analyses, so 77(51.3\%) male and 73(48.7\%) female were analyzed. The median age of the patients was 61 (range 18-84) years, 71(41.3\%) patients with ECOG PS 0-1 vs. 79(52.7\%) patients with ECOG PS $\geq 2$. Detail results about clinical stage, extra nodal involvement, elevated LDH, BMI, weight loss, revised IPI, NRS2002, pathohistology and type of chemotherapy are presented in (Table 1). Nutritional status was significantly different in patients with worse ECOG PS, but there was no significant difference in age groups, clinical stage or gender (Table 2). Analysing PFS according to nutritional status we have

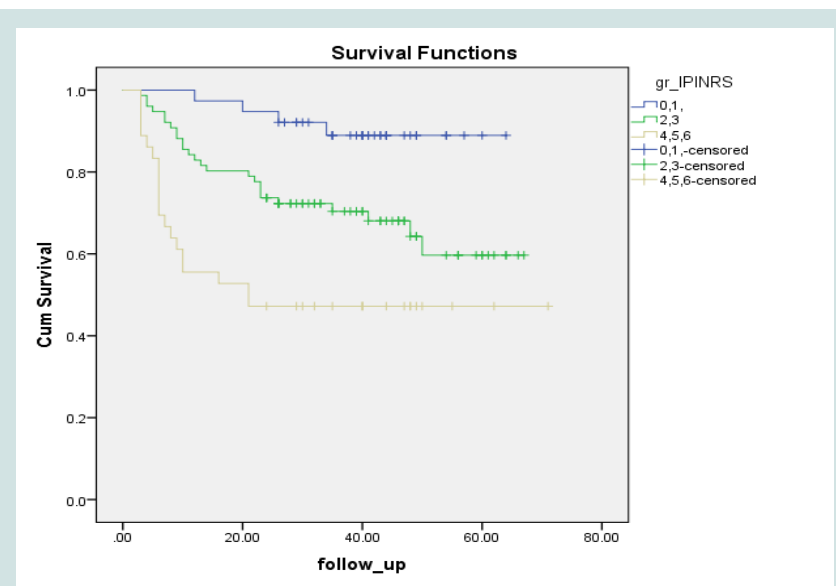

Graph 2: Kaplan Meier curve of progression free survival taking into account combined score IPI and NRS2002.

Table 2: Differences in frequencies of nutritional screening assessment in accordance to clinical characteristics of patients.

\begin{tabular}{|l|c|c|c|c|c|c|c|}
\hline \multicolumn{7}{|c|}{ NRS 2002} & \\
\hline Gender & 2 & 3 & 4 & 5 & 6 & $\mathrm{X}^{2}$ & $\mathrm{p}$ \\
\hline Male & & & & & & & \\
\hline Female & 31 & 13 & 17 & 14 & 2 & 4.775 & 0.311 \\
\hline Age & 30 & 20 & 14 & 9 & 0 & & \\
\hline$\leq 60$ years & & & & & & & \\
\hline$>60$ years & 30 & 15 & 14 & 9 & 1 & 0.711 & 0.95 \\
\hline Clinical stage & 31 & 18 & 17 & 14 & 1 & & \\
\hline I,II & & & & & & & \\
\hline III, IV & 28 & 12 & 9 & 8 & 1 & 2.888 & 0.577 \\
\hline ECOG PS & 33 & 21 & 22 & 15 & 1 & & \\
\hline 0,1 & & & & & & & \\
\hline$\geq 2$ & 40 & 15 & 11 & 5 & 0 & 17.775 & 0.001 \\
\hline
\end{tabular}


Citation: Djurasinovic V, Sipetic-Grujicic S, Antic D, Vukovic V, Bila J, et al. The Nutritional Status of Patients with Diffuse Large B cell Lymphoma Does it Matter?. J Nutri Health. 2018;4(2): 4.

found that there was significant difference in accordance of nutritional status showed on Graph 1. Patients with NRS2002 score more than 5, identifying patients with severe malnutrition, had shorter PFS (Mean: 19.4 with 95\%CI: 8.23-29.88 months, Median: 7 with 95\%CI: 2.3511.65 months) than groups with normal (Mean: 56.7 with 95\%CI: 52.2-61 months) or in risk of malnutrition (Mean: 42.3 with $95 \% \mathrm{CI}$ : 34.4-50.3 months). Long rank test was 23.3 , df2 and $p \leq 0.001$.

In this study we have created a new prognostic score by adding NRS $2002 \geq 3$ valued as 1 point on the revised IPI score. Thus, our new score which summarizes these two scores has maximum 6 points: age $\geq 60$ years, clinical stage $\geq \mathrm{III}$, elevated LDH over normal, ECOG PS $\geq 2$, extranodal disease and added NRS 2002 $\geq 3$, each of them 1 point $[7,8]$. Dividing patients in three groups with sum total $0,1 \leq$ 2,3 $\geq 4,5,6$ Kaplan-Meier curve showed statistically highly significant better progression free survival rates for pts with the new score IPINRS (Mean: 59.5 $\pm 2.1,95 \%$ CI 55.3-63.7 vs. $49.2 \pm 2.9$, 95\%CI: 43.4 54.9 vs. 37.8 \pm 5.3 , 95\%CI: 27.4-48.1; Log-Rank chi-square 18.9, df2 p0.001, Breslow chi-square 23.3, df 2, p0.001, Graph 2).

\section{Discussion}

Our observational study explored the importance of pretreatment nutritional status in patients with DLBCL and its influence on progression free survival. More than half of the group had ECOG PS $\geq 2$ and CS $\geq$ III and that is certainly linked to a worse nutritional status at the moment of disease presentation. All the included patients were eligible for curative treatment and were treated with immunochemotherapy according to current oncology guidelines. In our population of patients with aggressive lymphoma the body weight loss was similar to what was previously reported by the ECOG group [9]. Patients ineligible for intensive treatment were excluded from the study and the selection bias of group heterogeneity was eliminated.

For nutritional screening the NRS2002 assessment was used. We have found that this assessment is applicable in daily practice and very helpful for the detection of malnutrition. It consists not only of parameters concerning BMI and weight loss but also type and severity of disease. There are some studies in NHL DLBCL that have shown the importance of a nutritional assessment at the time of diagnosis but there are not studies using NRS2002 assessment [3]. As parameters for assessing nutritional status they have used middle arm muscle circumference, BMI and biochemical parameters-serum albumin, prealbumin and transferin in 262 pts with NHL DLBCL treated with R CHOP. In that study, only the BMI in multivariable analysis has shown statistical significance in overall survival. Another published study included 87 pts with DLBCL and showed significantly shorter survival and disease-free survival times in malnourished pts than in normally nourished ones [10]. There is one larger study evaluating the nutritional status of cancer patients published in 2012 by Bozzeti et al. using NRS2002. This large study found that almost one third of cancer pts presents a high nutritional risk [11]. Nowadays oncologists are not yet so familiar with the nutritional assessment tools. Symptoms like anorexia and fatigue in pts must alert them to care about the nutritional status. Although nutritional screening has been recommended since 2002, it is rarely performed [12]. In our study we applied this screening to group of lymphoma patients eligible for intensive treatment. An impaired nutritional status at the time of diagnosis has an influence on the treatment intensity and number of treatment complications. It has already been shown that malnourished patients require longer hospitalization and a higher treatment cost because of frequent complications [13].

We are aware of the limitation of our study. One is a lack of comparison of tumors mass at the time of presentation and the correlation with IPI scores. This potentially opens new possibilities to analyze and correlate nutritional status with the widely used R-IPI.

The impaired nutritional status in our study has been shown to be an important patient related prognostic parameter as ECOG PS for the prediction of treatment effectiveness and progression free survival. That is one more reason to force nutritional screening and to use it routinely. The R-IPI score includes ECOG PS but it is possible that the implementation of nutritional assessment may increase the probability and validity of this score. In our study, this assessment was more powerful than the clinical stage of the pts, which is also a part of the R-IPI score.

As part of the nutritional status at presentation, co-morbidities also play an important role in the treatment planning. Our study did not investigate the influence of co-morbidities but to eliminate selection bias we excluded pts ineligible for curative treatment. Unfortunately, there were some patients with impaired ECOG PS who were treated intensively with an unfavorable outcome. This study has demonstrated that the nutritional assessment seems to be very important as analyzing the quality of life, which is already included in clinical studies.

Using targeted therapies, like anti CD20 antibodies, has significantly improved survival in lymphoma pts. Modern research is focused on new targeting therapies in oncology, but the endpoints are deemed very important. As has already been published, the oncology wall can be opened with the correct words-defining favorable outcomes related to nutrition [14]. Detailed initial screening of important parameters can help us to reveal high risk patients. We need further studies to evaluate this finding.

Perhaps the implementation of knowledge in supportive treatment can obtain improvement in the outcomes of lymphoma pts.

\section{References}

1. Lory L, Linch D (2013) Non hodgkin lymphoma. In: Harrison C, Radia D (Eds), Medicine. 41: 282-289.

2. Sehn LH, Berry B, Chhanabhai M, Fitzgerald C, Gill K, et al. (2007) The revised International Prognostic Index (R-IPI) is a better predictor of outcome than the standard IPI for patients with diffuse large B-cell lymphoma treated with R-CHOP. Blood 109: 1857-1861.

3. Park S, Han B, Cho JW, Woo SY, Kim S, et al. (2014) Effect of nutritional status on survival outcome of diffuse large B cell lymphoma patients treated with rituximab-CHOP. Nutr Cancer 66: 225-233.

4. Kondrup J, Allison SP, Elia YM, Vellas B, Plauth M, et al. (2003) ESPEN guidelines for nutrition screening 2002. Clin Nutr 22: 415-421.

5. Guigoz Y (2006) The Mini Nutritional Assessment (MNA) review of the literature+-What does it tell us? J Nutr Health Aging 10: 466-487.

6. Rosenberg SA (1977) Validity of the Ann Arbor staging classification for the non-Hodgkin's lymphomas. Cancer Treat Rep 61: 1023-1027.

7. Jaffe ES (2009) The 2008 WHO classification of lymphomas: implications for clinical practice and translational research. Hematology Am Soc Hematol Educ Program 2009: 523-531. 
Citation: Djurasinovic V, Sipetic-Grujicic S, Antic D, Vukovic V, Bila J, et al. The Nutritional Status of Patients with Diffuse Large B cell Lymphoma Does it Matter?. J Nutri Health. 2018;4(2): 4.

\section{ISSN: $2469-4185$}

8. Swerdlow SH, Campo E, Harris NL, Jaffe ES, Pileri SA, et al. (2008) WHO Classification of tumours of haematopoietic and lymphoid tissues. ( $\left.4^{\text {th }} \mathrm{edn}\right)$ Lyon: International Agency for Research on Cancer 2: 586.

9. Dewys WD, Begg C, Lavin PT, Band PR, Bennett JM, et al. (1980) Prognostic effect of weight loss prior to chemotherapy in cancer patients. Eastern Cooperative Oncology Group. Am J Med 69: 491-497.

10. Aviles A, Yanez J, Lopez T, Garcia EL, Guzman R, et al. (1995) Malnutrition as an adverse prognostic factor in patients with diffuse large cell lymphoma. Arch Med Res 26: 31-34.

11. Bozzetti F, Mariani L, Lo Vullo S, SCRINIO Working Group, Amerio ML, et al.
(2012) The nutritional risk in oncology: a study of 1,453 cancer outpatients. Support Care Cancer 20: 1919-1928.

12. ASPEN Board of Directors and the Clinical Guidelines Task Force (2002) Guidelines for the use of parenteral and enteral nutrition in adult and pediatric patients. JPEN J Parenter Enteral Nutr 26 (1 Suppl): 1SA-138SA.

13. Norman K, Pichard C, Lochs H, Pirlich M (2008) Prognostic impact of disease-related malnutrition. Clin Nutr 27: 5-15

14. Laviano A, Fearon KC (2013) The oncology wall: Could Ali Baba have got to the nutrition treasure without using the correct words? Clin Nutr 32: 6-7. 